\title{
Comparison of renal profile in obese hypertensive and non-obese hypertensive patients at a Tertiary Care Hospital - A two year study
}

\author{
Bhaktavachalam Prudhvi ${ }^{1}$, Aparna Pottepalem ${ }^{2, *}$ \\ Assistant Professor, Dept. of Biochemistry, ACSR Medical College, Nellore, Andhra Pradesh, India \\ *Corresponding Author: \\ Email: sujatha2481@gmail.com
}

\begin{abstract}
Introduction: Obesity is a nutritional disorder and associated with excess fat deposition due to altered balance between energy intake and consumption. Obesity and obesity related hypertension are identified as risk factors in development of diabetes and chronic kidney disease. Obesity alters the hemodynamic functions of organs and is a threat for development of cardiovascular diseases, renal failure and peripheral arterial disease.

Objectives: The objective of the present study was to compare the renal profile among healthy individuals, obese individuals, obese with preexisting hypertension and obese individuals without hypertension.

Materials and Methods: A prospective cross sectional observational study was conducted at ACSR government medical college and hospital, a tertiary care hospital for a period of two years from October 2014 to September 2016. 120 subjects were divided into 4 groups with 30 in each group, healthy, obese, non obese hypertensive and obese hypertensives.

Results: All the measured variables in all the four groups of the study were expressed as mean \pm standard deviation. BMI of $32.1 \pm 2.1$ was observed in obese group whereas $22.1 \pm 3.1$ was observed in healthy group. Statistically significant correlation was found with BMI, S. urea, S. creatinine, S. uricacid and estimated Glomerular filtration rate ('p' value $<0.005$ ).

Discussion: To conclude, obesity related metabolic abnormalities and impairment of renal function may present even at a young age and may progress asymptomatically before the development of clinical manifestations. Hence there is a need to develop global strategy for maintaining the increased number of overweight and obese patients in the community.
\end{abstract}

Keywords: Body Mass Index, Estimated Glomerular filtration rate, Hypertension, Obesity, Renal profile.

Received: $10^{\text {th }}$ October, 2017

\section{Introduction}

Obesity and Hypertension are important public challenges which are increasing worldwide. Increased prevalence of obesity throughout the world is recognized as an important risk factor in development of hypertension. Obesity is a nutritional disorder and associated with excess fat deposition due to altered balance between energy intake and consumption. Excess energy and decreased consumption causes excess weight gain which can cause changes in the functions of organs. ${ }^{1}$ Obesity and obesity related hypertension are identified as risk factors in development of diabetes and chronic kidney disease. The prevalence of obesity is mostly seen in urban areas than rural and women are more associated than men globally. Prevalence of obesity among western population was high but an alarming rise is now observed in developing countries due to changed life style and unhealthy food habits. ${ }^{2}$

Obesity alters the hemodynamic functions of organs and is a threat for development of cardiovascular diseases, renal failure and
Accepted: $06^{\text {th }}$ November, 2017

peripheral arterial disease. Higher Body mass index (BMI) is associated with the presence and development of proteinuria in individuals without kidney disease. ${ }^{3}$ In many large population based studies, higher BMI is associated with presence and development of low estimated glomerular filtration rate, with more rapid loss of estimated GFR over time and with the incidence of ESRD. ${ }^{4}$ Obesity is also associated with an increased risk of development of nephrolithiasis and various types of malignancies. Obesity results in complex metabolic abnormalities that have wide ranging effects on diseases of the kidney. Increased adipose tissue in obesity may lead to increased secretion of adiponectin, leptin and resistin which may result in development of inflammation, oxidative stress, abnormal lipid metabolism, and increased production of insulin and insulin resistance. ${ }^{5}$ Obesity causes kidney injury through direct mechanisms through deranged synthesis of adipose tissue cytokines with nephrotoxic potential as well as indirectly by triggering diabetes and hypertension. ${ }^{6}$ 
Studies on role of obesity alone on renal functions are limited and hence the present study was done to know the individual role of obesity on renal profile along with hypertension. The objective of the present study was to compare the renal profile among healthy individuals, obese individuals, obese with preexisting hypertension and obese individuals without hypertension.

\section{Materials and Methods}

A prospective cross sectional observational study was conducted at ACSR government medical college and hospital, a tertiary care hospital for a period of two years from October 2014 to September 2016. The study was approved by the institutional ethical committee and all the standard procedures were followed in collection of the data. By using simple random sampling methodology, 120 subjects including 60 subjects attending the general medicine ward were included and divided into four groups based upon the inclusion criteria. Demographic variables of the cases were noted by interviewing and noted in a separate proforma which include age, weight and height. History of hypertension, any medication, $\mathrm{H} / \mathrm{O}$ of diabetes mellitus, were enquired and noted. BMI of every case was calculated and cases with BMI >30 were categorized as obese, $<30$ as non obese and if between $18.5-24.9$ were placed as healthy with normal BMI. All the 120 cases were placed in 4 Groups:

Group I: 30 Obese Non hypertensive patients.

Group II: 30 Obese Hypertensive patients.

Group III: 30 Non Obese Hypertensive patients.

Group IV: 30 healthy controls with normal BMI.

\section{Exclusion Criteria}

a. Cases with $<30$ and $>60$ years.

b. Preexisting Renal disease, Known Diabetics., Serious co-morbid illnesses

c. Patients on Thiazide group of diuretic drug in Group II \& III,

d. BMI $<18.5 \& 25$ in Group IV.

All the anthropometric parameters were measured/ calculated as per the standard guidelines.

\section{Sample Collection}

Under aseptic precautions $4 \mathrm{ml}$ of blood was collected from the antecubital vein using aseptic precautions in a plain vacutainers for estimation of renal parameters. Urine sample was collected in a sterile urine container for urinary protein analysis.

All serum samples were analyzed by using fully automated analyzer Thermo scientific. All the analytical reagents were standardized before instrument was calibrated before analysis. Urine analysis for protein was done by using commercially available Dip stick method.

1. Estimation of serum urea was done by Enzymatic urease- Glutamate dehydrogenase (GLDH) method. ${ }^{7}$

2. Estimation of Serum creatinine was done by Modified Jaffe's method. ${ }^{8}$

3. Estimation of Serum uric acid was done by using Modified Trinder peroxidise method. ${ }^{9}$

\section{Statistical analysis}

All the results were expressed in Mean \pm standard deviation. The data analysis was done by using SPSS version 15.0 (U.S.A). Unpaired student ' $t$ ' test was used for comparision in between the groups. Pearson's correlation coefficient test was done to test the correlation between serum urea, serum creatinine, serum uric acid and eGFR. Chi-Square test was done for urinary excretion of protein for comparison between study groups. ' $p$ ' value $<0.05$ was considered statistically significant.

\section{Results}

The present study was done to compare the renal function in age matched obese and non obese hypertensive patients in comparison with healthy and normal obese group to study the effect of BMI and both systolic and diastolic blood pressure on renal function by estimating the renal parameters which include Blood urea, Serum creatinine, Serum uric acid and estimated Glomerular Filtration Rate.

There was no significant difference in the age of the cases in different groups of the study. Males were predominant in the study with $67.5 \%$ in comparison with females who were only $32.5 \%$ in the study. [Table 1] [Fig. 1]

Table 1: Age wise distribution of study groups

\begin{tabular}{|c|c|c|c|c|}
\hline \multirow{2}{*}{$\begin{array}{c}\text { Age (in } \\
\text { Years) }\end{array}$} & Healthy & $\begin{array}{c}\text { Non-obese } \\
\text { Hypertensive } \\
\text { patients }\end{array}$ & Obese & $\begin{array}{c}\text { Obese } \\
\text { Hypertensive } \\
\text { patients }\end{array}$ \\
\hline $\mathbf{3 0 - 4 0}$ & 11 & 11 & 11 & 10 \\
\hline $\mathbf{4 1 - 5 0}$ & 12 & 11 & 11 & 12 \\
\hline $\mathbf{5 1 - 6 0}$ & 7 & 8 & 8 & 8 \\
\hline
\end{tabular}




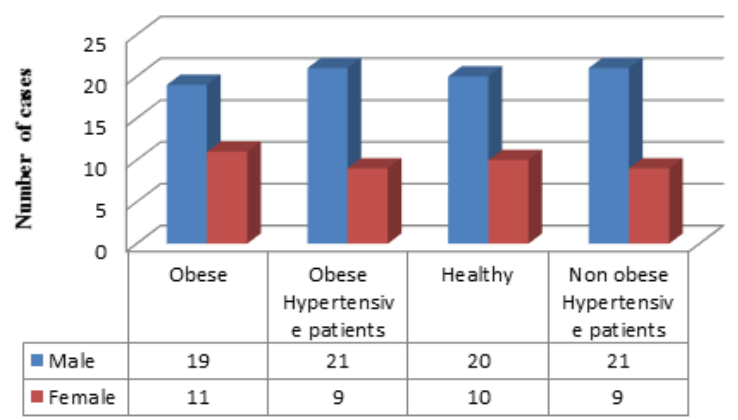

Fig. 1: Sex wise distribution of cases in the study

All the measured variables in all the four groups of the study were expressed as mean \pm standard deviation and shown in Table 2. BMI of $32.1 \pm 2.1$ was observed in obese group whereas $22.1 \pm 3.1$ was observed in healthy group. The SBP was $141.18 \pm 2.9 \mathrm{~mm}$ hg and DBP was $85.14 \pm 2.9$ in obese hypertensives in the study. Serum urea was $36.1 \pm 1.8$, Serum creatinine was $1.11 \pm 0.23$ and eGFR was $94.2 \pm 22.2$ among obese hypertensives in the study.

Table 2: Distribution of variables in study groups

\begin{tabular}{|c|l|c|c|c|c|}
\hline \multirow{2}{*}{$\begin{array}{c}\text { S. } \\
\text { No }\end{array}$} & \multirow{2}{*}{ Variables } & \multicolumn{4}{|c|}{ Values expressed as mean \pm SD } \\
\cline { 3 - 6 } & & \multicolumn{4}{|c|}{ Study Groups } \\
\cline { 3 - 5 } & & Obese (Gr-I) & OH (Gr-2) & NOH (Gr-3) & Healthy (Gr-4) \\
\hline 1 & Age (yrs) & $42.1 \pm 6.1$ & $46.4 \pm 7.2$ & $45.4 \pm 6.2$ & $44.1 \pm 8.3$ \\
\hline 2 & Weight (kgs) & $90.4 \pm 5.8$ & $88.2 \pm 6.5$ & $66.1 \pm 8.3$ & $61.14 \pm 5.1$ \\
\hline 3 & Height (Sq Mts) & $1.70 \pm 0.6$ & $1.71 \pm 2.1$ & $1.68 \pm 2.1$ & $1.67 \pm 2.8$ \\
\hline 4 & BMI & $32.1 \pm 2.1$ & $31.8 \pm 1.8$ & $23.1 \pm 4.1$ & $22.1 \pm 3.1$ \\
\hline 5 & SBP (mm Hg) & $121.2 .8 \pm 4.5$ & $141.18 \pm 2.9$ & $140.2 \pm 3.8$ & $120.14 \pm 3.4$ \\
\hline 6 & DBP (mm Hg) & $78.12 \pm 2.9$ & $85.14 \pm 2.9$ & $83.12 \pm 2.8$ & $76.12 \pm 2.8$ \\
\hline 7 & Blood glucose (mg/dl) & $83 \pm 2.0$ & $86 \pm 2.8$ & $75.0 \pm 1.4$ & $72 \pm 3.2$ \\
\hline 8 & Serum Urea(mg/dl) & $27.1 \pm 2.8$ & $36.1 \pm 1.8$ & $21.4 \pm 2.4$ & $20.1 \pm 2.0$ \\
\hline 9 & S.creatinine(mg/dl) & $0.86 \pm 0.02$ & $1.11 \pm 0.23$ & $0.70 \pm 0.12$ & $0.7 \pm 0.01$ \\
\hline 10 & S.uric acid(mg/dl) & $4.3 \pm 0.56$ & $4.3 \pm 0.47$ & $3.83 \pm 0.30$ & $3.8 \pm 0.28$ \\
\hline 11 & e GFR (ml/minute) & $138.5 \pm 17$ & $94.2 \pm 22.2$ & $116.1 \pm 7.7$ & $120.6 \pm 6.7$ \\
\hline
\end{tabular}

OH: Obese Hypertensive; NOH: Non obese Hypertensive; SBP: Systolic Blood pressure; DBP: Diastolic Blood pressure

Table 3 shows comparison between obese and healthy group. Statistically significant correlation was found with BMI, S.urea, S.creatinine, S.uricacid and estimated Glomerular filtration rate. ('p' value $<0.005$ ). Further comparison between healthy and obese hypertensive's revealed a statistically significant correlation between BMI, SBP, DBP and renal parameters in the study subjects ('p' value $<0.005$ ) which is summarized in Table 4. Correlation study done to know the effect of BMI and blood pressure, demonstrated highly significant positive correlation (at 0.001 level) of BMI with both systolic and diastolic blood pressure in obese hypertensive patients only. BMI also showed significant positive correlation in relation to S.creatinine, S.uricacid and eGFR in obese hypertensive patients only.

Table 3: Independent ' $t$ ' test between Healthy and Obese patients

\begin{tabular}{|c|l|c|c|c|c|}
\hline S. No & \multicolumn{1}{|c|}{ Test Variables } & \multicolumn{2}{c|}{ Values expressed as mean \pm SD } & $\mathbf{t}^{\prime}$ value & $\mathbf{p}^{\prime}$ value \\
\hline & & Healthy & Obese & & \\
\hline 1 & Age & $44.1 \pm 8.3$ & $42.1 \pm 6.1$ & 0.249 & 0.758 \\
\hline 2 & BMI & $22.1 \pm 3.1$ & $32.1 \pm 2.1$ & 28.55 & 0.001 \\
\hline 3 & SBP $(\mathrm{mm} \mathrm{Hg})$ & $120.14 \pm 3.4$ & $121.2 .8 \pm 4.5$ & 1.586 & 0.105 \\
\hline 4 & DBP $(\mathrm{mm} \mathrm{Hg})$ & $76.12 \pm 2.8$ & $78.12 \pm 2.9$ & 0.001 & 0.948 \\
\hline 5 & Serum Urea & $20.1 \pm 2.0$ & $27.1 \pm 2.8$ & 4.028 & 0.0001 \\
\hline 6 & S.creatinine & $0.7 \pm 0.01$ & $0.86 \pm 0.02$ & 7.541 & 0.0001 \\
\hline 7 & S.uric acid & $3.8 \pm 0.28$ & $4.3 \pm 0.56$ & 3.5 & 0.001 \\
\hline 8 & e GFR (ml/minute) & $120.6 \pm 6.7$ & $138.5 \pm 17$ & 6.542 & 0.0001 \\
\hline
\end{tabular}


Table4: Independent ' $t$ ' test between Healthy and Obese hypertensive patients

\begin{tabular}{|c|c|c|c|c|c|}
\hline \multirow[t]{2}{*}{ S.No } & \multirow[t]{2}{*}{ Test Variables } & \multicolumn{2}{|c|}{ Values expressed as mean \pm SD } & \multirow[t]{2}{*}{ 't' value } & \multirow[t]{2}{*}{$\mathbf{p}^{\prime}$ value } \\
\hline & & Healthy & OH & & \\
\hline 1 & Age & $44.1 \pm 8.3$ & $46.4 \pm 7.2$ & 1.015 & 0.28 \\
\hline 2 & BMI & $22.1 \pm 3.1$ & $31.8 \pm 1.8$ & 24.86 & 0.0001 \\
\hline 3 & SBP (mm Hg) & $120.14 \pm 3.4$ & $141.18 \pm 2.9$ & 15.86 & 0.0001 \\
\hline 4 & $\mathrm{DBP}(\mathrm{mm} \mathrm{Hg})$ & $76.12 \pm 2.8$ & $85.14 \pm 2.9$ & 8.98 & 0.0001 \\
\hline 5 & Serum Urea & $20.1 \pm 2.0$ & $36.1 \pm 1.8$ & 10.54 & 0.0001 \\
\hline 6 & S.creatinine & $0.7 \pm 0.01$ & $1.11 \pm 0.23$ & 9.5 & 0.0001 \\
\hline 7 & S.uric acid & $3.8 \pm 0.28$ & $4.3 \pm 0.47$ & 4.1 & 0.0001 \\
\hline 8 & e GFR (ml/minute) & $120.6 \pm 6.7$ & $94.2 \pm 22.2$ & -4.984 & 0.0001 \\
\hline
\end{tabular}

Table 5 shows the comparison between healthy and non obese hypertensive's in the study. Significant difference was not observed with BMI and renal parameters, but significant difference was observed in relation to both systolic and diastolic blood pressure.

Table 5: Independent ' $t$ ' test between Healthy and Non Obese Hypertensive patients

\begin{tabular}{|c|c|c|c|c|c|}
\hline \multirow[t]{2}{*}{ S.No } & \multirow[t]{2}{*}{ Test Variables } & \multicolumn{2}{|c|}{ Values expressed as mean \pm SD } & \multirow[t]{2}{*}{ 't' value } & \multirow[t]{2}{*}{$\mathbf{p}^{\prime}$ value } \\
\hline & & Healthy & NOH & & \\
\hline 1 & Age & $44.1 \pm 8.3$ & $45.4 \pm 6.2$ & 1.12 & 0.275 \\
\hline 2 & BMI & $22.1 \pm 3.1$ & $23.1 \pm 4.1$ & 1.458 & 0.142 \\
\hline 3 & $\mathrm{SBP}(\mathrm{mm} \mathrm{Hg})$ & $120.14 \pm 3.4$ & $140.2 \pm 3.8$ & 14.658 & 0.0001 \\
\hline 4 & DBP (mm Hg) & $76.12 \pm 2.8$ & $83.12 \pm 2.8$ & 8.574 & 0.0001 \\
\hline 5 & Serum Urea & $20.1 \pm 2.0$ & $21.4 \pm 2.4$ & -0.206 & 0.846 \\
\hline 6 & S.creatinine & $0.7 \pm 0.01$ & $0.70 \pm 0.12$ & 0.347 & 0.712 \\
\hline 7 & S.uric acid & $3.8 \pm 0.28$ & $3.83 \pm 0.30$ & 0.47 & 0.684 \\
\hline 8 & e GFR (ml/minute) & $120.6 \pm 6.7$ & $116.1 \pm 7.7$ & -1.854 & 0.049 \\
\hline
\end{tabular}

Table 6 demonstrates the comparison between obese hypertensive's and non obese hypertensives in the study. No significant differences were observed in age and blood pressure ('p' value $>0.005$ ) among these two groups but significant differences were observed in relation to BMI and renal profile ('p' value $<0.005$ ). BMI also showed significant positive correlation in relation to serum creatinine, serum uric acid and eGFR in obese hypertensive patients only.

Table 6: Independent ' $t$ ' test between Obese Hypertensive and Non Obese Hypertensive patients

\begin{tabular}{|c|c|c|c|c|c|}
\hline \multirow[t]{2}{*}{ S. No } & \multirow[t]{2}{*}{ Test Variables } & \multicolumn{2}{|c|}{ Values expressed as mean \pm SD } & \multirow[t]{2}{*}{ t' value } & \multirow[t]{2}{*}{$\mathbf{p}^{\prime}$ value } \\
\hline & & OH & NOH & & \\
\hline 1 & Age & $46.4 \pm 7.2$ & $45.4 \pm 6.2$ & 0.242 & 0.843 \\
\hline 2 & BMI & $31.8 \pm 1.8$ & $23.1 \pm 4.1$ & 24.1 & 0.0001 \\
\hline 3 & SBP $(\mathrm{mm} \mathrm{Hg})$ & $141.18 \pm 2.9$ & $140.2 \pm 3.8$ & 1.895 & 0.059 \\
\hline 4 & $\mathrm{DBP}(\mathrm{mm} \mathrm{Hg})$ & $85.14 \pm 2.9$ & $83.12 \pm 2.8$ & 1.094 & 0.27 \\
\hline 5 & Serum Urea & $36.1 \pm 1.8$ & $21.4 \pm 2.4$ & 11.12 & 0.0001 \\
\hline 6 & S.creatinine & $1.11 \pm 0.23$ & $0.70 \pm 0.12$ & 9.145 & 0.0001 \\
\hline 7 & S.uric acid & $4.3 \pm 0.47$ & $3.83 \pm 0.30$ & 3.457 & 0.001 \\
\hline 8 & e GFR (ml/minute) & $94.2 \pm 22.2$ & $116.1 \pm 7.7$ & -4.547 & 0.0001 \\
\hline
\end{tabular}


Fig. 2 shows significant difference in urinary excretion of proteins between obese hypertensive patients and non obese hypertensive patients in the study. ('p' value $<0.001$ )

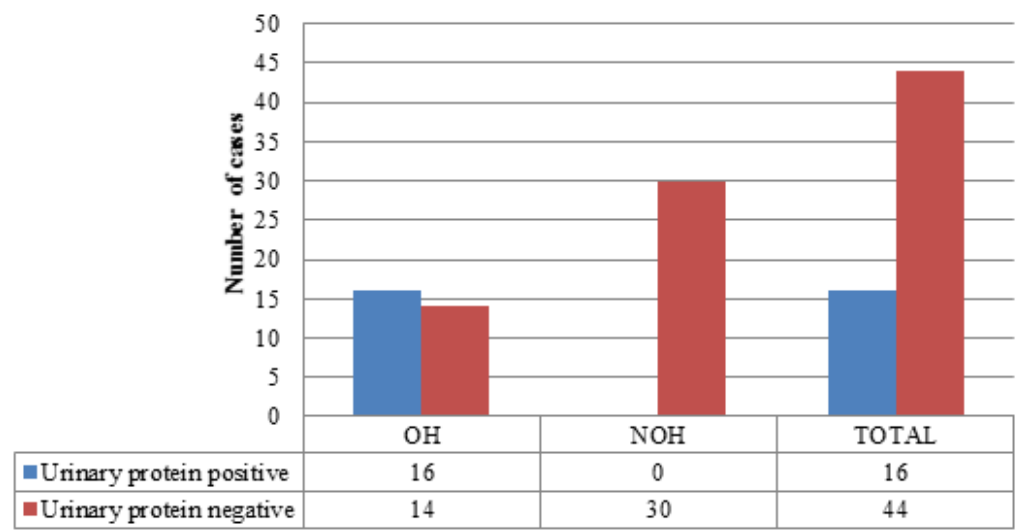

Fig. 2: Comparison of obese hypertensive and non-obese hypertensive patients in terms of urinary proteins

\section{Discussion}

The present study was conducted in a tertiary care hospital to assess and compare the renal function in healthy individuals, obese, obese hypertensives and non obese hypertensives. BMI was taken as a measure of obesity and blood pressure was calculated in all the cases of the study. Males were common in the study than females.

In our study, statistically significant correlation was found with BMI, S.urea, S.creatinine, S.uricacid and estimated Glomerular filtration rate between obese and healthy individuals. Findings of our study were similar to the findings of Sandhu JS et al who found significant correlation of BMI with renal profile among obese individuals. ${ }^{10}$ Findings in our study was almost parallel to the findings of Kaufmann JS who also found a significant association between BMI, systolic blood pressure, diastolic blood pressure, and renal parameters between obese hypertensives and non obese hypertensives demonstrating that obesity is an risk factor in development of hypertension which in turn leads to progressive damage to the kidneys altering the renal parameters and finally to chronic kidney disease. ${ }^{11}$

However most of the studies universally have related obesity in development of obesity related glomerulopathy and foal segmental glomerulosclerosis which signifies the association of hypertension as a co risk factor in renal damage. ${ }^{12}$ Neeraja Kambham et al in their studies concluded that obesity related glomerulopathy, is different from idiopathic focal segmental glomerulosclerosis consistent with presence of features of glomerulomegaly. ${ }^{13}$
From the observation and results found in our study, a significant difference was found in BMI and lipid profile between obese hypertensive and non obese hypertensive patients. However we could not find the time taken for the renal effects to develop in obese hypertensive patients. Accurate data and comprehensive studies regarding the factors are lacking.

To conclude, obesity related metabolic abnormalities and impairment of renal function may present even at a young age and may progress asymptomatically before the development of clinical manifestations. Recent findings in the study of Kincaid-Smith proposed that obesity and insulin resistance syndrome play a major role in genesis of renal failure in hypertensive patients which has been labeled as hypertensive nephrosclerosis. ${ }^{14}$ Hence there is a need to develop global strategy for maintaining the increased number of overweight and obese patients in the community.

\section{References}

1. Forouzanfar MH, Alexander L, Anderson HR, et al. Global, regional, and national comparative risk assessment of 79 behavioural, environmental and occupational, and metabolic risks or clusters of risks in 188 countries, 1990-2013: a systematic analysis for the Global Burden of Disease Study 2013. Lancet. 2015;386:2287-323.

2. Kambham N, Markowitz GS, Valeri AM, Lin J, D’Agati VD. Obesity-related glomerulopathy: An emerging epidemic. Kidney Int. 2001;59:1498509.

3. Wang Y, Chen X, Song Y, Caballero B, Cheskin LJ. Association between obesity and kidney disease: A systematic review and meta-analysis. Kidney Int. 2008;73:19-33. 
4. Gelber RP, Kurth T, Kausz AT, et al. Association between body mass index and CKD in apparently healthy men. Am J Kidney Dis. 2005;46:871-80.

5. Ruster C, Wolf G. The role of the reninangiotensin-aldosterone system in obesity-related renal diseases. Semin Nephrol.2013;33:44-53

6. Stenvinkel P, Marchlewska A, Pecoits-Filho R, et al. Adiponectin in renal disease: relationship to phenotype and genetic variation in the gene encoding adiponectin. Kidney Int.2004;65:27481.

7. Talke, H. and Schubert, G. E. Klin, Wochschr., (1965) 19,43:174.] [Tiffany, T.O. Jansen, J., Burtis C. A. Overton J. B. and Scott C. D. Clin.Chem. (1972) 18:829.

8. Tanganelli,E, Prencipe, L, Bassi D, Cambiaghi S and Murador E., Clin.Chem. 1982;28;7;1461-4.

9. Kabasakalian P., Kalliney, S. and Wescott A., Clin. Chem., 1973,19;522.

10. Sandhu JS, Singla M, Ahuja A, Soni A, Chopra P. Renal risks of obesity. J Indian Acad Clin Med.2004;5:335-8.

11. Kaufman JS, Durazo-Arvizu RA, Rotimi CN, McGee DL, Cooper RS: Obesity and hypertension prevalence in populations of African origin. The Investigators of the International Collaborative Study on Hypertension in Blacks. Epidemiology 1996;7:398-405.

12. Wickman, C. \& Kramer, H. Obesity and kidney disease: potentialmechanisms. Semin. Nephrol.33,14-22 (2013).

13. Neeraja kambham, glen s. Markowitz, 124ulie124y m. Valeri, 124ulie lin, vivette d, d'agati. Obesity-related glomerulopathy: An emerging epidemic, Kidney International. 2001;59:1498-509.

14. Kincaid-Smith P. Hypothesis: obesity and the insulin resistance syndrome play a major role in end-stage renal failure attributed to hypertension and labelled 'hypertensive nephrosclerosis'. J Hypertens 2004;22:1051-5. 